Thorax (1969), 24, 78.

\title{
A review of the management of 140 elective tracheostomies following open-heart surgery
}

\author{
R. D. MAR SHALL \\ From St. Bartholomew's Hospital, London ${ }^{1}$
}

\begin{abstract}
A retrospective survey of 140 cases of elective tracheostomy following open-heart surgery has been undertaken. All the tracheostomies were performed by surgeons of the Cardiac Unit using a standard technique during the years 1962 to 1966 inclusive. The indications during this period are discussed and possible reasons for the high incidence of tracheostomy are considered. The complications have been carefully assessed. The results indicate that, although there is room for improvement, a reduction in the number and severity of complications has been achieved. In particular there have been few late sequelae, which is attributed to good surgical technique and the adoption of the Björk operation. In $60 \%$ of the patients there were no complications; one death was directly attributable to tracheostomy.
\end{abstract}

The experience of Lassen (1953) in the poliomyelitis epidemic which occurred in Copenhagen in 1952 led to the general adoption of artificial ventilation by intermittent positive pressure (I.P.P.V.) in the treatment of respiratory failure, and, in consequence, the tank respirator has been largely abandoned in the acute disease. The increase in use of this form of therapy has of necessity been accompanied by a rise in the number of tracheostomies performed.

A retrospective survey of all tracheostomies undertaken in Oxford from 1950 to 1959 has been published by McClelland (1965). He reported an increase in the use of the operation over the years and drew attention to the high complication rate and mortality. At St. Bartholomew's Hospital there has been a similar increase in the use of tracheostomy, but, with the experience of previous workers to draw upon, we have been able to reduce morbidity and mortality.

Tracheostomy is no longer reserved for the desperately ill patient in respiratory failure: unhurried surgery under endotracheal anaesthesia is now the rule rather than the exception (Spencer, 1966), and the use of cuffed tracheostomy tubes, adequate humidification, a sterile suction procedure, and controlled ventilation have all helped to reduce the incidence of complications.

'Present address : Northampton General Hospital

\section{MATERIAL AND METHODS}

One reason for the increase in the number of tracheostomies performed has been the use of I.P.P.V. following open-heart surgery in the years 1962 to응 1966 inclusive (Fig. 1). These form an interesting and $\stackrel{\varrho}{a}$ well-defined group for the purpose of assessing the $\overrightarrow{\vec{\sigma}}$ incidence of complications in a series where the 3 indications for tracheostomy were relatively constant? and the patients were under the care of experiencedo personnel. Such an assessment is particularly appropriate in view of recent articles (Tonkin and Harrison. 1966) and annotations (B.M.J., 1967 ; Lancet, 1967) which have considered the complications of tracheo- $-x$ stomy in comparison with prolonged endotracheal intubation.

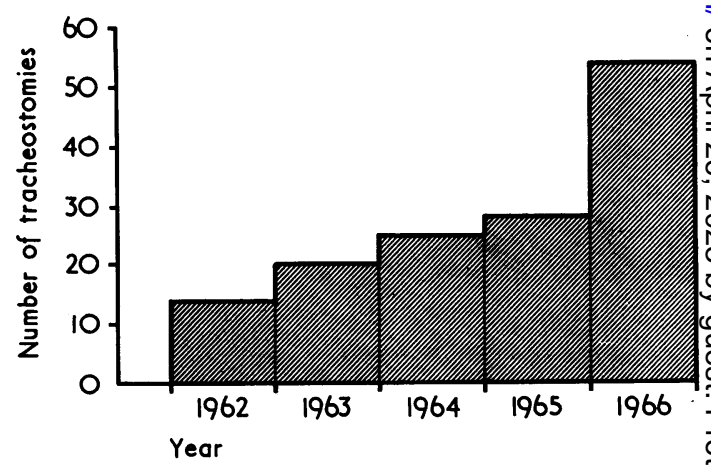

FIG. 1. Elective tracheostomies following open-heart surgery, 1962-66. 
INDICATIONS On occasions some surprise has been expressed at the number of tracheostomies performed in our unit. However, it must be emphasized that open-heart surgery is developing so rapidly that policies may change in a few months. In the years in question our main post-operative problems were pulmonary complications, including the ventilation perfusion defect commonly known as 'pump.lung' (Nahas, Melrose, Sykes, and Robinson, 1965).

This high incidence of pulmonary complications may have been related to three factors:

1. The type of case undertaken: for example, our series includes many of mitral valve disease with a raised pulmonary vascular resistance (Hamer, 1967).

2. The use of a high proportion of blood in the primes of the heart-lung machine: a haemodilution technique is now practised (Robertson, 1968).

3. The administration of excessively high oxygen concentrations in the post-operative period. It now seems possible that this may lead to a loss of surfactant and cause alveolar damage even when the oxygen is humidified and delivered by I.P.P.V. (Lee, Lyons, Konisberg, Morgan, and Moore, 1967).

The desaturation due to the post-perfusion lung syndrome reaches a peak on the third or fourth postoperative days, and our policy was to perform tracheostomy and ventilate (especially where there were other indications) in order to maintain a high inspired oxygen concentration over this period. It now seems possible that this high concentration of oxygen aggravated, or was the cause of, the pulmonary condition, and, since becoming aware of this danger, our management has changed. Oxygen enrichment is now limited to that necessary for maintenance of a normal blood oxygen tension, and we believe that this has reduced the incidence of pulmonary complications and has made it possible to limit ventilation to the immediate post-operative period by using an endotracheal tube for 12 to 36 hours.

The indications for elective tracheostomy during the period under review were divided into two main groups, primary pathological factors and secondary operative factors (Table I).

\section{T A B L E I}

INDICATIONS FOR ELECTIVE TRACHEOSTOMY FOLLOWING OPEN-HEART SURGERY, 1962-66

\begin{tabular}{|c|c|c|c|}
\hline \multicolumn{3}{|l|}{ Indication } & No. \\
\hline $\begin{array}{l}\text { Primary pathological factors } \\
\text { Raised pulmonary vascular } \\
\text { Congestive cardiac failure } \\
\text { Associated lung pathology } \\
\text { Tetralogy of Fallot . } \\
\text { Second bypass procedure } \\
\text { Miscellaneous }\end{array}$ & 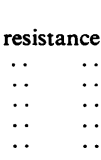 & $\begin{array}{l}\ldots \\
\ldots \\
\ldots \\
\ldots \\
\ldots\end{array}$ & $\begin{array}{l}42 \\
32 \\
26 \\
19 \\
11 \\
22\end{array}$ \\
\hline $\begin{array}{l}\text { Secondary operative factors } \\
\text { Inadequate ventilation } \\
\text { Conduction defects or dysrh } \\
\text { Prolonged procedure } \\
\text { Difficulty in weaning from } \\
\text { Cardiac arrest } . . \\
\begin{array}{ll}\text { Miscellaneous } & . .\end{array}\end{array}$ & \begin{tabular}{cc}
\multicolumn{2}{c}{$\ldots$} \\
hythmias \\
oypass & $\ldots$ \\
$\ldots$ & $\ldots$ \\
$\ldots$ & $\ldots$
\end{tabular} & $\begin{array}{l}\ldots \\
\cdots \\
\cdots \\
\cdots \\
\cdots\end{array}$ & $\begin{array}{r}20 \\
19 \\
17 \\
10 \\
5 \\
6\end{array}$ \\
\hline
\end{tabular}

$55 \%$ of patients presented more than one indication.
The primary group included all patients in whom the indications for tracheostomy were known before surgery. These patients ventilated poorly postoperatively and almost invariably needed some form of assistance. Originally, it was considered that a raised pulmonary vascular resistance, frequently in the range of 10 to 25 units, was practically an absolute indication for elective tracheostomy and I.P.P.V.; but more recently, since the policy with regard to oxygen already outlined has been adopted, we have successfully managed a patient with a pulmonary vascular resistance of 22 units by endotracheal intubation and ventilation for 36 hours. Severe congestive cardiac failure resistant to medical treatment has been another common indication. 'Lung pathology', excluding pulmonary hypertension, formed a third group and included a wide variety of conditions. Of these, bronchitis was the most common, but bronchospasm, emphysema, pulmonary fibrosis, and recent pulmonary tuberculosis all occurred. In one patient the left pulmonary artery was thrombosed. An elective tracheostomy was performed on nearly all patients suffering from cyanotic Fallot's tetralogy, as non-elective tracheostomy had proved necessary in a few earlier cases; the results have justified this policy in this particular condition. A number of patients who had valve repairs or valvotomies in the early years later required valve replacement and underwent a second bypass procedure. In the majority of these, elective tracheostomy was performed at the second operation. The miscellaneous group covers a variety of conditions, including preoperative haemolytic anaemia, neurological disorders, personality problems, and those patients in the over60 age group.

Secondary indications include those that arose as the direct result of anaesthesia, surgery, or perfusion. The most common of these was inadequate spontaneous ventilation at the end of anaesthesia as judged clinically, by the Wright respirometer and on the results of blood gas analysis. In a number of these patients the indications were borderline, but at that time our policy was to ventilate post-operatively via an elective tracheostomy rather than via an endotracheal tube. The remaining indications were primarily the results of problems created by surgery or perfusion. In particular when conduction defects or disorders of rhythm occurred it was wise to ensure adequate ventilation and oxygenation, and this was best achieved by controlled ventilation (EdmondsSeal, 1966). Over-ventilation in the presence of a low serum potassium and haemodilution may of itself lead to ventricular fibrillation (Barnard, Saunders, Eales, and Barnard, 1966).

SURGICAL TECHNIQUE One hundred and forty elective tracheostomies were performed by the surgeons of the cardiac unit using a standard technique. The operations were performed in the theatre under endotracheal anaesthesia following completion of the cardiac surgery. All were of the Björk type (Björk, 


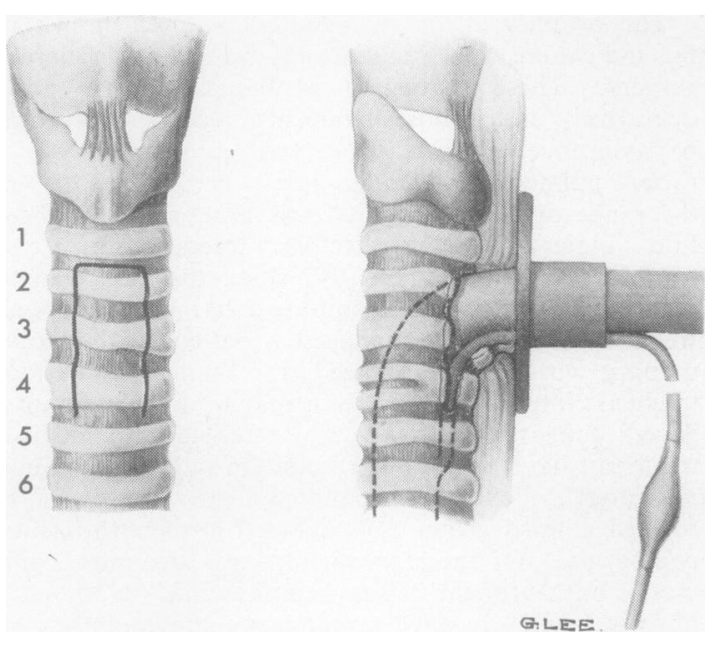

FIG. 2. Björk tracheostomy.

1960), in which a flap of anterior tracheal wall is turned forwards and sutured to the lower skin edge of the neck incision (Fig. 2). A small transverse skin incision was used routinely and sutures were rarely required to close the extremities of the wound.

The choice of tracheostomy tube was important. The largest size possible was used to facilitate ventilation and suction; a 42 French gauge or its equivalent was suitable for most adult men and a 39 French gauge for most adult women. Originally a MorrantBaker tube with a latex cuff was favoured, but when these became unobtainable a James pattern was used. Both these tubes are made of red rubber, and the James has an acute angle which may impede the passage of a suction catheter. A polyvinyl chloride tube made by Portex (Whittard and Thomas, 1964), which has a curve similar to the Morrant-Baker but may prove less irritant, has been used for later cases

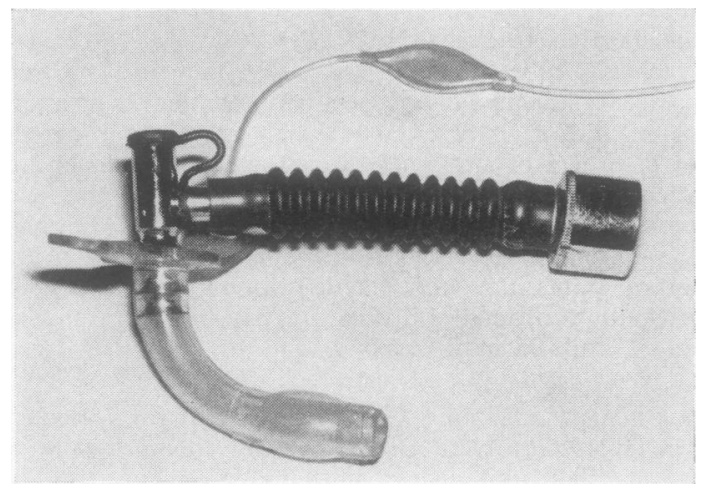

FIG. 3. Portex tracheostomy tube, Cobbs suction union, and catheter mount. in the series. Portex have specially modified this $\vec{\Rightarrow}$ tube by removing the chimney originally provided $\stackrel{5}{+}$ for a Nosworthy connexion, and it is now suitable for use with the Cobbs suction union, which is preferred (Fig. 3).

MANAGEMENT On completion of the tracheostomy all patients were returned to the thoracic recovery $\infty$ unit and remained there until the tracheostomy tube $\overrightarrow{0}$ was removed. This unit was staffed day and night by qualified nurses trained in the care of this parti- $\vec{\omega}$ cular type of patient. Supervision of the tracheostomy and ventilation was the responsibility of a resuscita- $\vec{x}$ tion registrar who was a member of the Department in of Anaesthesia and was available throughout the 24. hours (Marshall, 1966). The value of a sterile suction $\vec{v}$ procedure (Fig. 4), adequate humidification, and in- $\infty$ tensive physiotherapy cannot be overstressed. Since 윽 1963 the tracheostomy tube has not been changed unnecessarily, and its early removal after weaning from the ventilator has become routine.

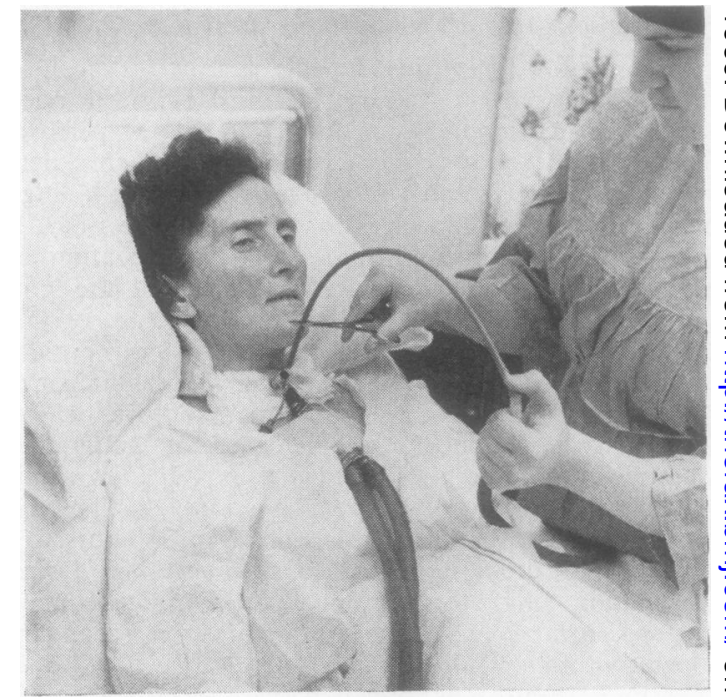

FIG. 4. Sterile suction technique. Note method of fixing to $\stackrel{\frac{D}{D}}{=}$ the chest, preventing movement of the tracheostomy tube $\mathrm{N}$ in the trachea and reducing the risk of displacement.

\section{RESULTS}

The ages of the 140 patients ranged from 4 to 68 years (Table II) and the duration of tracheo- $\mathbb{D}$ stomy from a few hours to 54 days, with an average of 10 days (Table III).

There were no complications in 84 patients $\stackrel{\circ}{\Phi}$ (60\%). Eighty-five complications occurred in the $\frac{\text { Pे }}{\mathbb{D}}$ remaining 56 patients $(40 \%)$. There was one death directly attributable to tracheostomy (a mortality 
T A B L E I I

AGE DISTRIBUTION OF ELECTIVE TRACHEOSTOMIES FOLLOWING OPEN-HEART SURGERY, 1962-66

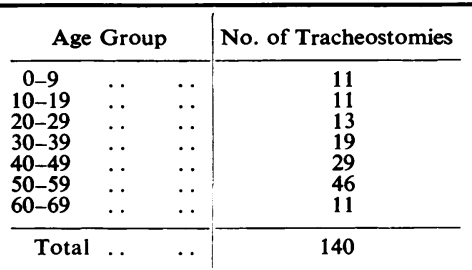

T A B L E I I I

DURATION OF ELECTIVE TRACHEOSTOMIES FOLLOWING OPEN-HEART SURGERY, 1962-66

\begin{tabular}{|c|c|c|}
\hline \multicolumn{2}{|l|}{ Days } & No. of Tracheostomies \\
\hline $\begin{array}{ll}0-2^{1} & \ldots \\
3-7 & \ldots \\
8-14 & \ldots \\
15-21 & \cdots \\
\text { More than } 22\end{array}$ & $\begin{array}{l}\cdots \\
\cdots \\
\cdots \\
\cdots\end{array}$ & $\begin{array}{r}17 \\
54 \\
42 \\
18 \\
9\end{array}$ \\
\hline Total ... & $\ldots$ & 140 \\
\hline
\end{tabular}

${ }^{1}$ All patients in this group died from causes not attributable to the tracheostomy.

of $0.7 \%$ ). These figures compare favourably with the reports of others, but most of these refer to general series including infants and not to elective tracheostomy within a specialized unit. McClelland (1965) reported a $49 \cdot 3 \%$ incidence of complications with a mortality of $3.4 \%$, and Hargrove (1967) estimates that complications occurred in $50 \%$ of all cases.

In assessing the complications of tracheostomy, the classification described by McClelland (1965) and Kodicek (1960) has been largely followed, but a preliminary subdivision into three main groups-operative, post-operative, and latesequelae - has been made (Table IV).

T A B LE IV

COMPLICATIONS OF ELECTIVE TRACHEOSTOMY FOLLOWING OPEN-HEART SURGERY, 1962-66

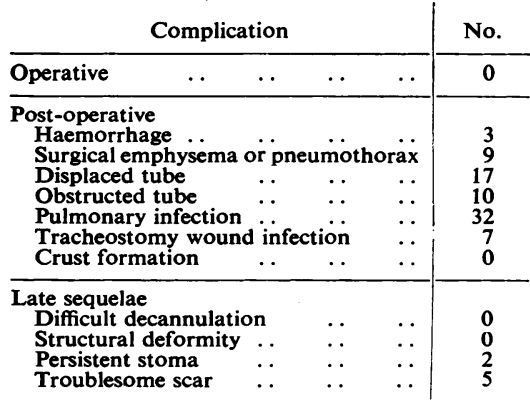

OPERATIVE COMPLICATIONS There were no complications at the time of operation. We believe that this was the result of surgery under endotracheal anaesthesia in the theatre. Complications can and do frequently occur when a tracheostomy is attempted as an emergency on an unintubated patient in the absence of a skilled anaesthetist.

POST-OPERATIVE COMPLICATIONS Severe haemorrhage occurred on three occasions. In one instance it caused complete obstruction of the tracheostomy tube. In two patients it was necessary to pack the tracheostomy wound to control bleeding. Trivial oozing from the skin edge of the tracheostomy wound, though common, has not been included.

Surgical emphysema occurred on seven occasions but was only severe once, when it was associated with a pneumothorax. Pneumothorax alone occurred twice.

The tracheostomy tube became partially or completely displaced from the lumen of the trachea on 17 occasions in 14 patients. On two occasions displacement of the tube led to cardiac arrest, and one patient died as a result of this despite vigorous resuscitative measures. On six occasions the tube was pulled out by the patient, and there were two instances of over-inflation of the cuff which led to partial displacement of the tube from the lumen of the trachea. Displacement of the tube is a serious complication, and is most likely to occur during the first 48 hours post-operatively. In this period replacement may be difficult, but the Björk flap minimizes the difficulties, and tracheal dilators, though available at the patient's bedside, are rarely necessary. The risk of displacement of the tracheostomy tube can be reduced by firm fixation of the catheter mount to the patient's chest with adhesive strapping (Fig. 4).

In 10 patients the tracheostomy tube became obstructed, though in nine of these the obstruction was only partial. In one patient the tube became completely obstructed by blood clot, necessitating its urgent removal. Two spare sterile tubes were kept at the patient's bedside-one tube the same size as that in the patient and one a size smaller in case difficulty was encountered in the change-over.

Pulmonary infection is a well-documented hazard of tracheostomy, and was not uncommon in our series. The figure in Table IV probably lays undue emphasis on this complication, for it includes all records in which the nurse reported aspirating even small quantities of what she 
regarded as purulent sputum over more than 24 hours. Radiological evidence of pulmonary infection was difficult to interpret, as the appearances of 'pump-lung' and pulmonary oedema frequently clouded the picture.

Although it has not been our habit to take swabs for culture from the tracheostomy wound routinely, inflammation was apparent in the neck incision on seven occasions. This always led to considerable discomfort, especially on swallowing, and was a reason for bitter complaints by the affected patients.

Crust formation has not been a problem in the series. This is attributed to adequate humidification via the ventilator during I.P.P.V. and early removal of the tube once adequate spontaneous respiration has been established. In the majority of cases the tube was removed within 12 hours of weaning from the ventilator. Even in this period humidification was maintained with either a vapour-condenser (Mapleson, Morgan, and Hillard, 1963) or blower humidifier and T-piece (Marshall, Jones, and Crichton, 1967).

LATE SEQUELAE There have been few late sequelae and those that have occurred have been of a minor nature.

Failure to adapt to removal of the tracheostomy tube has never been a problem even with children.

There were no cases of tracheal stenosis. We believe that this was the result of good surgical technique and the Björk operation, though Deverall (1967) reported six cases of tracheal obstruction requiring excision of the stricture after Björk tracheostomies. Three cases of stenosis have occurred elsewhere in the hospital during the same period, but none of these was truly an elective procedure nor were they Björk tracheostomies. To our knowledge neither tracheal dilatation nor ulceration occurred in the five-year period under review, but one case of ulceration into a major vessel has occurred since. As the importance of deflating the cuff of the tracheostomy tube is frequently stressed by others (Gibson, 1967), it is worth recording that our policy has been to inflate the cuff with the minimum volume of air required to maintain an airtight seal and then not to allow it to be routinely released. However, the majority of cuffs gradually deflate over a period of time and require replenishment with air.

The tracheal stoma was slow to heal on two occasions, but neither required operative closure.
Five patients complained about the scar at the first follow-up visit following discharge from hospital. In two others it was adherent, causing dis- $\frac{0}{\bar{c}}$ comfort on swallowing. In a 7-year-old child? the scar became keloid. In the remaining two å slight discharge persisted for a number of weeks.

More than one complication occurred in $a \rightarrow$ number of patients, as is illustrated by the following case history.

T. D., aged 13 years, had a closure of a ventricular septal defect (previous incomplete correction of tetra- $-\underset{\perp}{-}$ logy of Fallot) and a Björk tracheostomy.

On the evening of operation it was necessary toos pack the tracheostomy wound to control persistento venous bleeding. Mild surgical emphysema involving mainly the face developed the same evening. The following morning difficulty was encountered when re-inserting the tracheostomy tube at a routine change, and it was necessary to summon an anaese thetist to perform oral intubation. (In the early part of this series it was the nurses' practice to changeo the tracheostomy tube routinely on the first post 6 operative morning.) Two days later the tracheostomy tube became displaced, leading to a cardiac arrest. The tube was rapidly replaced and the patient was successfully resuscitated. Despite the aspiration of purulent sputum for two days it was possible to weano the patient off the ventilator on the seventh and $\mathbb{P}^{\mathrm{P}}$ eighth days and the tracheostomy tube was removed $\overrightarrow{\vec{b}}$ on the ninth day.

In all there were five complications in this case and it can be seen that two of these nearly caused the patient's death.

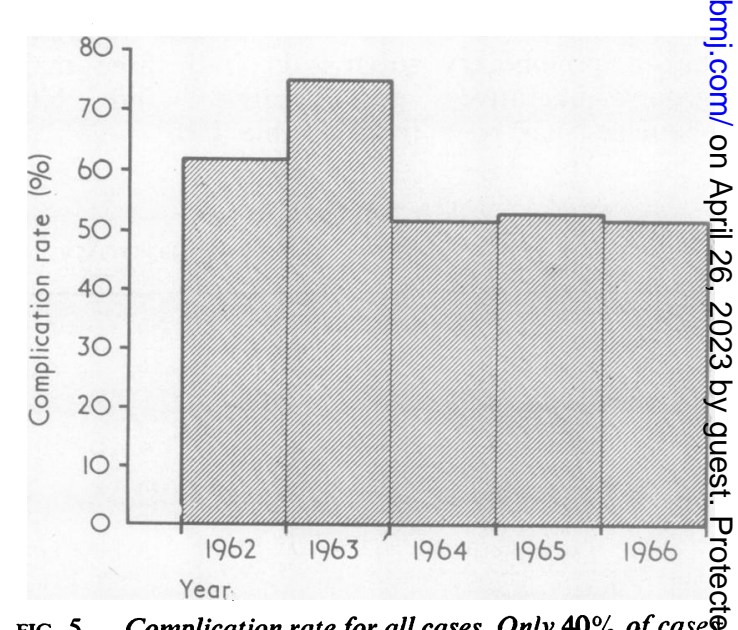

FIG. 5. Complication rate for all cases. Only $40 \%$ of case had complications, but many had more than one complica tion. 


\section{DISCUSSION}

Figure 5 shows the percentage of complications that occurred in all patients and not the number of tracheostomies with complications, as some had more than one. In the last three years the rate has remained constant at approximately $50 \%$, which is a considerable improvement over the first two years. Although Fig. 5 fails to show a further decline in the number of complications since the beginning of 1964 , the severity of these has been considerably reduced.

We believe that such success as we have achieved can be attributed to a better understanding of the problems and to the establishment of a satisfactory routine, but that there is room for improvement. For example, now that the administration of a humidified air-oxygen mixture to the spontaneously respiring patient has been considerably simplified, it is possible that the duration of I.P.P.V. can be reduced, and it may be that this will result in a further fall in the number of complications.

The author would like to thank Mr. O. S. Tubbs and Mr. I. M. Hill for allowing him access to the notes of the patients under review; Miss L. Farrar for providing a considerable amount of data, including that for Fig. 1 ; Dr. T. B. Boulton for advice and assistance; the Department of Medical Illustration for the figures; and Miss Joan Goodwin for secretarial assistance.

\section{REFERENCES}

Barnard, M. S., Saunders, S. J., Eales, L., and Barnard, C. N. (1966). Hypokalaemia during extracorporeal circulation. Lancet, 1, 240.
Björk, V. O. (1960). Partial resection of the only remaining lung with the aid of respirator treatment. J. thorac. cardiovasc. Surg., 39, 179.

British Medical Journal (1967). Prolonged endotracheal intubation (Annotation), 1, 321.

Deverall, P. B. (1967). Tracheal stricture following tracheost omy. Thorax, 22, 572.

Edmonds-Seal, J. (1966). Acid-base studies after cardiac arrest. Acta anaesth. scand., Suppl. 23, p. 235.

Gibson, P. (1967). Aetiology and repair of tracheal stenosis following tracheostomy and intermittent positive pressure respiration. Thorax, 22, 1 .

Hamer, N. A. J. (1967). Mitral valve replacement. St. Bart. Hosp. J., 71, Clinical and research supplement No. 18, p. vi.

Hargrove, R. L. (1967). In Tracheostomy and Artificial Ventilation in the Treatment of Respiratory Failure, ed. Feldman, S. A., p. 44. Edward Arnold, London.

Kodicek, J. M. (1960). The place and management of tracheostomy in respiratory insufficiency, J. Laryng., 74, 891.

Lancet (1967). Endotracheal intubation or tracheostomy (leading article), 1, 258.

Lassen, H. C. A. (1953). A preliminary report on the 1952 epidemic of poliomyelitis in Copenhagen with special reference to the treatment of acute respiratory insufficiency, Lancet, $1,37$.

Lee, C. J., Lyons, J. H., Konisberg, S., Morgan, F., and Moore, F. D. (1967). Effects of spontaneous and positive-pressure breathing of ambient air and pure oxygen at one atmosphere pressure on pulmonary surface characteristics. J. thorac. cardiovasc. Surg.,

Mapleson, W. W., Morgan, J. G., and Hillard, E. K. (1963). Assessment of condenser-humidifiers with special reference to a multiplegauze model. Brit. med. J., 1, 300.

Marshall, R. D. (1966). The role of the Resuscitation Registrar in the recovery period, St. Bart. Hosp. J., 70, Clinical and research supplement No. 14, p. vii.

_ Jones, N. O., and Crichton, T. C. (1967). A T-piece for use with a blower-humidifier. Anaesthesia, 22, 494.

McClelland R. M. A. (1965). Complications of tracheostomy. Brit. med.J., 2, 567.

Nahas, R. A., Melrose, D. G., Sykes, M. K., and Robinson, B. (1965). Post-perfusion lung syndrome. Lancet, 2, 251, 254.

Robertson, D. S. (1968). Large volume haemodilution for open-heart surgery. Anaesthesia (in press).

Spencer, G. T. (1966). In A Practice of Anaesthesia, ed. Wylie, W. D., and Churchill-Davidson, H. C., 2nd ed., p. 400. Lloyd-Luke, London.

Tonkin, J. P., and Harrison, G. A. (1966). The effect on the larynx of prolonged endotracheal intubation. Med. J. Aust., 2, 581.

Whittard, B. R., and Thomas K. E. (1964). A "new" polyvinylchloride cuffed tracheostomy tube. Lancet, 1, 797. 